\title{
Burkitt-Like Lymphoma Post-Transplant Lymphoproliferative Disorder
}

National Cancer Institute

\section{Source}

National Cancer Institute. Burkitt-Like Lymphoma Post-Transplant Lymphoproliferative Disorder. NCl Thesaurus. Code C7245.

A Burkitt-like lymphoma that arises in a patient with a history of organ transplantation. 